\title{
In the news
}

\section{BOLD MOVES}

Two 2012 Lasker awards gave recognition to US-based biologists. The Basic Medical Research award was shared by Michael Sheetz (Columbia University), James Spudich (Stanford University) and Ronald Vale (University of California, San Francisco) for their characterization of molecular motors. This award acknowledges the many years of endeavour, begun by Spudich in the 1970s, to reconstitute motor-driven movement in vitro. This culminated in the development of in vitro motility reconstitution assays in the early 1980s for both myosin and kinesin, the latter of which was identified by Vale and Sheetz. The physiological relevance of the many kinesins and myosins found since is now being re-emphasized with the ongoing development of drugs that target these proteins in disease. This award "recognizes the work of daring and determined scientists who revealed the awe-inspiring mechanics of the tiny motor proteins that drive the cellular world," commented Maria Freire (President of the Lasker Foundation, 10 Sep 2012).

The Lasker-Koshland Special Achievement Award in Medical Science was given to Donald Brown (Emeritus Director at the Carnegie Institution for Science) and Tom Maniatis (Columbia University) for their 1970s research into the nature of genes and their strong support of research beyond the bench. Their studies established DNA recombinant technology and the techniques required for such experiments. Maniatis gave the global community access to these methods through his landmark publication, Molecular Cloning. "The important thing is the international impact," said Maniatis, "... it basically taught a generation of scientists how to use the tools" (The New York Times, 10 Sept 2012). And Brown, wanting to provide support for young investigators, established the Life Sciences Research Foundation and ensured its maintenance during the past 30 years. Alison Schuldt 